\title{
Vibration research of heavy trucks. Part 2: Optimization of vehicle dynamic parameters
}

\author{
Yong Ye ${ }^{1}$, Vanliem Nguyen ${ }^{2}$, Yongzhu $\mathrm{Hu}^{3}$ \\ School of Mechanical and Electrical Engineering, Hubei Polytechnic University, Huangshi, 435003, China \\ Hubei Key Laboratory of Intelligent Conveying Technology and Device, Hubei Polytechnic University, \\ Huangshi, 435003, China \\ ${ }^{2}$ Corresponding author

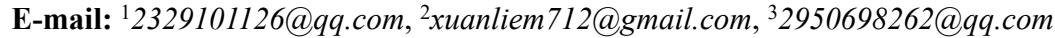

Received 2 November 2020; accepted 24 November 2020

DOI https://doi.org/10.21595/jmeacs.2020.21814

Check for updates

Copyright $(C 2020$ Yong Ye, et al. This is an open access article distributed under the Creative Commons Attribution License, which permits unrestricted use, distribution, and reproduction in any medium, provided the original work is properly cited.

\begin{abstract}
In order to enhance the ride comfort, stability, and safety of heavy trucks. Based on the dynamic characteristics of the parameters of heavy trucks and its dynamic model, a multi-objective genetic algorithm are developed in the MATLAB environment and applied to optimize the dynamic parameters of vehicles. The weighted root-mean-square (RMS) accelerations of the cab and driver seat vibrations are chosen as the study goals to evaluate the results under different vehicle conditions. The obtained results show that the optimal parameters of vehicles are significantly enhanced the vehicle ride comfort under different operation conditions. Particularly, the weighted RMS accelerations of the $a_{w z}$ and $a_{w \varphi c}$ are significantly reduced by $26.3 \%$ and $35.3 \%$ under the ISO level B of the road surface, and a vehicle speed region from $17.5 \mathrm{~m} / \mathrm{s}$ to $20 \mathrm{~m} / \mathrm{s}(63 \mathrm{~km} / \mathrm{h}$ to $72 \mathrm{~km} / \mathrm{h})$.
\end{abstract}

Keywords: heavy trucks, dynamic parameters, multi-objective genetic algorithm, ride comfort .

\section{Introduction}

The heavy vehicles are not only required to enhance the ride comfort but also required the improvement of the road friendliness. In order to solve this problem, the heavy truck suspension system ought to be able to isolate the sprung mass from road-induced disturbances as well as reducing the dynamic-load-coefficient of tire force from the axle of the heavy trucks within the limit of set working space under different operator conditions [1-4].

The ride comfort of vehicles has been greatly affected by the design parameters of the vehicles, especially parameters of the vehicle suspension systems. Therefore, researchers have continuously developed advanced suspension systems such as air suspension systems [5,6], semi-active suspension systems [7-9], or the control suspensions of the cab [10,11]. The research results have also significantly improved the vehicle's ride comfort while traveling. However, previous studies have often focused on optimizing or controlling an individual suspension system, an overall rating of the car that is less considered. Besides, the published studies is shown that the semi-active suspension systems can improve the vehicle's ride better than its optimized suspension parameters $[1,12,13]$. However, the installation of the controlled suspension can lead to an increase in the price. In addition, for heavy trucks, the vehicle is often used by with three suspension systems with the different damping and stiffness parameters for the vehicle, cab, and driver's seat. Therefore, all the vehicle suspension systems equipped with the control suspensions are impossible. Previous studies were only concerned with controlling the vehicle suspension system $[5,7,12]$ or the suspension system of the cab and seat $[11,14]$ to improve the ride comfort. There are no studies to suggest suspension control for the whole system. For heavy trucks are supported by various suspensions of the vehicle, cab, and seat; it can be more efficient if the optimization of their dynamic parameters and control of a vehicle or cab suspension system. However, multi-objective optimization of the parameters of heavy truck suspension systems is a complex problem, and it has not yet fully paid attention $[12,13]$.

Based on a vehicle dynamic model and an optimal region of the vehicle dynamic parameters 
proposed in Part-1, a multi-objective genetic algorithm is developed and applied to optimize the vehicle dynamic parameters. The weighted RMS accelerations of the vertical driver's seat and cab pitch angle have been used to evaluate the vehicle ride comfort under the different simulation conditions of the road surfaces and speeds. The aim of this study is the optimization of the vehicle dynamic parameters to improve vehicle ride comfort.

\section{Mathematical model}

\subsection{The dynamic model of heavy trucks}

Based on research results in Part-1, the dynamic parameters of the vehicle suspension system with the vehicle dynamic model are plotted in Fig. 1, where, $z_{s}, z_{c}, z_{b}, z_{t}$, and $z_{a i}$ are the displacements in the $z$-direction of the seat, cab, body, trailer, and axle; $\varphi_{c}, \varphi_{b}$, and $\varphi_{t}$ are the pitch angles of the cab, body, and trailer, respectively; $C_{s}, C_{c n}, C_{i}$, and $C_{t i}$ are the damping parameters of the suspension systems of the seat, cab, vehicle, and wheel, respectively; $K_{s}, K_{c n}$, $K_{i}$, and $K_{t i}$ are the stiffness parameters of the suspension systems of the seat, cab, vehicle, and wheel, respectively; $m_{s}, m_{c}, m_{b}, m_{t}$, and $m_{a i}$ are the mass of the seat, cab, body, trailer, and vehicle's unsprung; $l_{m}$ are all geometric dimensions $(i=1, \ldots, 3, n=1,2, m=1, \ldots, 9)$.

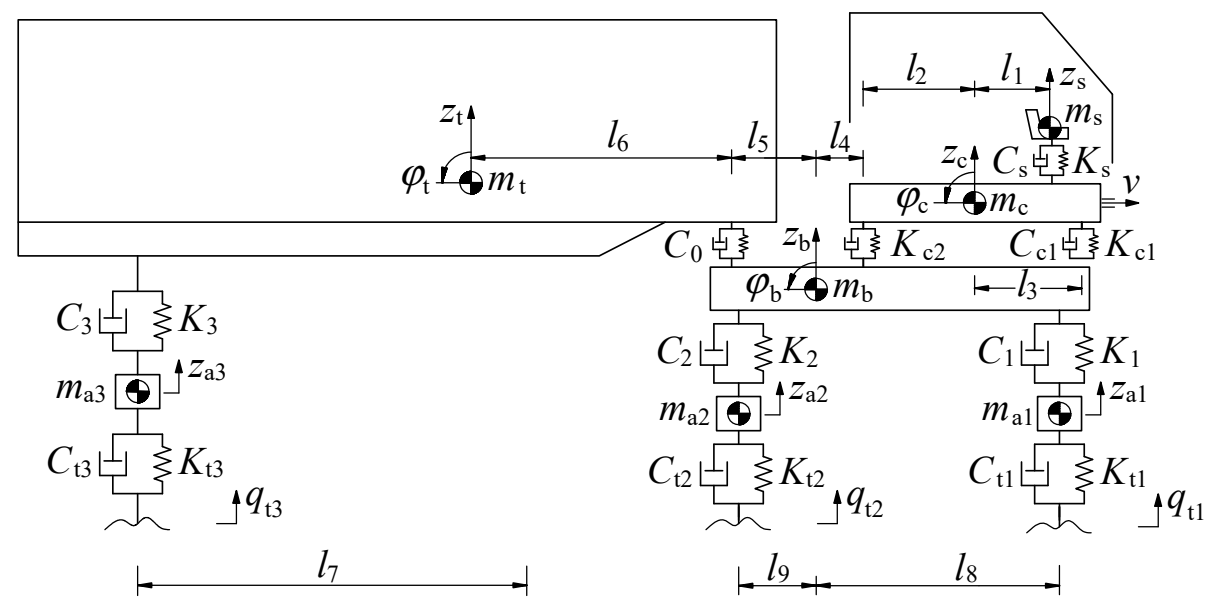

Fig. 1. Lumped parameter model of heavy trucks

Based on the lumped parameter model of the vehicle in Fig. 1 and Newton-II law, the motion equations of the vehicle is represented by the matrix form as in Eq. (1):

$M \ddot{Z}+C \dot{Z}+K Z=F_{q}(t)$,

where $M, C, C_{a}$, and $K$ are the matrices of the mass, passive damping, active damping, and stiffness of the vehicle, $Z$ is the displacement vector, and $F_{q}(t)$ is the excitation force vector of the vibrations from the road surface.

\subsection{Road surface roughness}

Based on the established method of the random road surface in Section 3 of Part-1, and according to the standard ISO 8068 [15], four types of level A to D of the road surface roughness are established and simulated at $72 \mathrm{~km} / \mathrm{h}$, as shown in Fig. 2. The excitation of these road surfaces is then applied for the simulation process of the vehicle. 

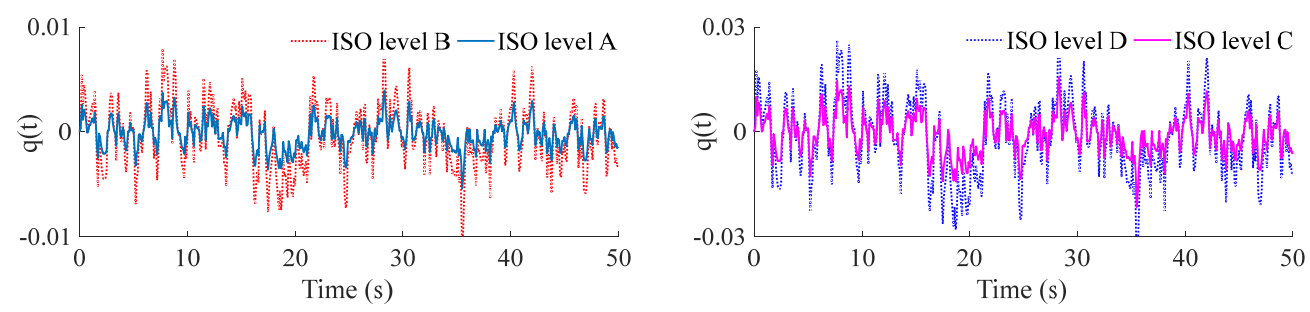

Fig. 2. Road profiles according to ISO 8068

\subsection{Evaluation criteria of ride comfort}

According to the ISO 2631-1 [16], the influence of the vibration on the driver's health and ride comfort had been mainly assessed through the weighted RMS (Root-Mean-Square) of the acceleration responses, and it is described as follows:

$a_{w z}=\sqrt{\frac{1}{T} \int_{0}^{T} a_{\mathrm{z}}^{2} d t}, \quad a_{w \varphi \mathrm{c}}=\sqrt{\frac{1}{T} \int_{0}^{T} a_{\varphi \mathrm{c}}^{2} d t}$,

where $a_{z}$ and $a_{\varphi c}$ are the acceleration responses of the driver's seat and cab that depend on the time of measurement $T$.

The weighted RMS acceleration responses of the vertical driver's seat and the pitch angle of the cab of heavy trucks can be calculated from Eq. (2), their values are then compared with $a_{w z}$, as given in Table 1.

\section{Optimization of the vehicle dynamic parameters}

\subsection{Multi-objective genetic algorithm (MGA)}

The MGA is a multi-optimization method via the natural selection, and it is defined as finding the Maximum or Minimum functions of one or more goals. Thus, the MGA is simply described by the mathematical method as follows [5, 17-18]:

Find the vector $a=\left[a_{1}, a_{2}, \ldots, a_{n}\right]^{T}$ for the optimization of the function $M(a)$ :

$M(a)=\left[m_{1}(a), m_{2}(a), \ldots, m_{n}(a)\right]^{T}$.

Subject to $g_{i}(a) \leq 0, i=1,2, \ldots, p, h_{j}(a)=0, j=1,2, \ldots, q$, where $M(a)$ is the vector of the study goals, and $M(a)$ must be obtained the Maximum or Minimum values. $p$ and $q$ are the boundary conditions of the optimal regions.

The MGA structure has been defined by the steps of "encoding, population initialization, fitness evaluation, parent selection, genetic operations (crossover and mutate), and termination criterion". Therefore, a flowchart of the MGA program for the optimization of the vehicle dynamic parameters is plotted in Fig. 3.

\subsection{Application of the GA for optimization of the vehicle dynamic parameters}

The goal of this study to apply the MGA is to optimize the parameters $\left\{C_{s}, C_{c n}, C_{i}, C_{t i}\right\}$ and $\left\{K_{s}, K_{c n}, K_{i}, K_{t i}\right\}$ of the damping and stiffness of the suspension systems of the seat, cab, vehicle, and wheel to reach the Minimum values of the weighted RMS values of the driver's seat vibration $\left(a_{w z}\right)$ and cab's pitch vibration $\left(a_{w \varphi c}\right)$ via the lumped parameter model of the vehicle and the AGA model in Figs. 1 and 3. Therefore, the MGA's structure has been established as follows:

(1) Encoding and initial populations: The dynamic parameters of $\left\{C_{s}, C_{c n}, C_{i}, C_{t i}\right\}$ and 
$\left\{K_{s}, K_{c n}, K_{i}, K_{t i}\right\}$ are connected to the chromosome regarded as the vectors to reduce the length of the chromosome and enhance the seeking speed of the AGA. Besides, the initial population, the generated individuals is random. With each gene, it is also randomly chosen in its region. In this study, the initial population size is established by 200 .

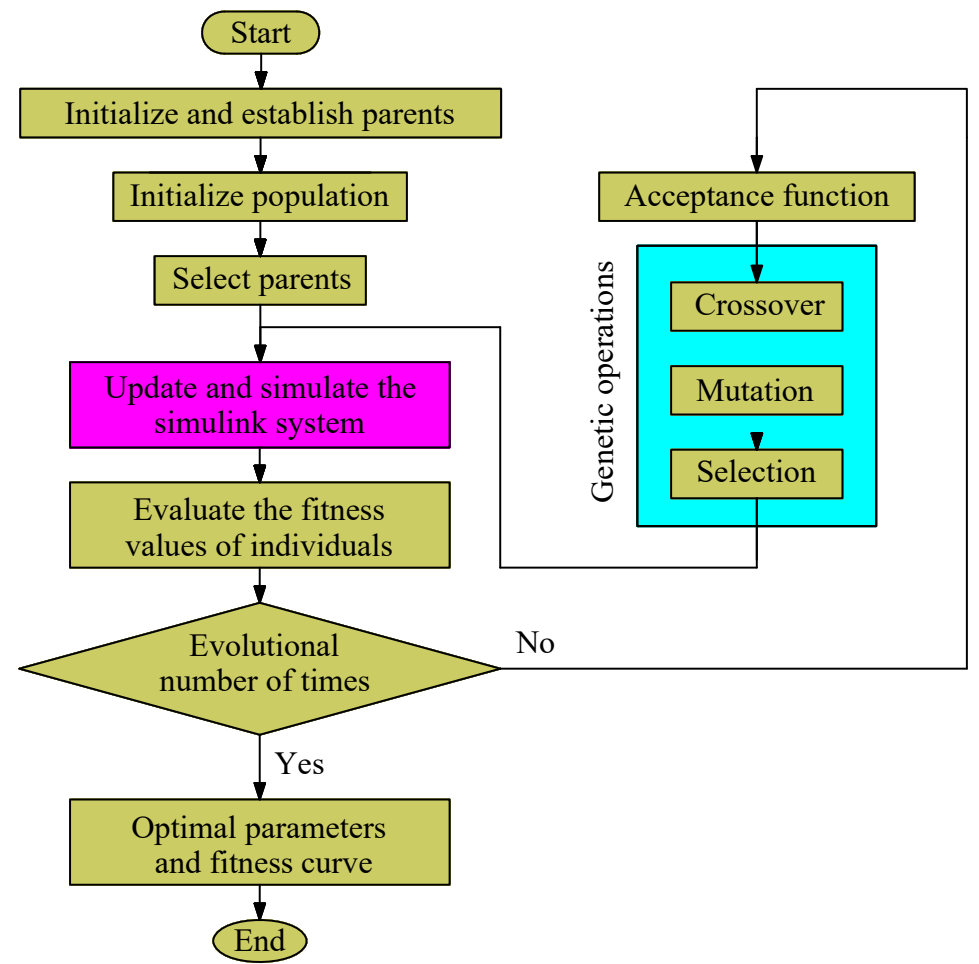

Fig. 3. The flowchart of the MGA

(2) Research values and fitness functions: In this study, the Minimum RMS values of the acceleration vibrations of the driver's seat $\left(a_{w z}\right)$ and cab $\left(a_{w \varphi c}\right)$ given in Eq. (2) have been chosen as the study aims. To research the Minimum RMS values of the acceleration vibrations, two fitness values of $J_{1}$ and $J_{2}$ are simplified to compute the study aims as follows [5]:

$J_{1}=\min \left\{a_{w z}\right\}, \quad J_{2}=\min \left\{a_{w \varphi c}\right\}$.

The individuals with the smaller fitness values $J_{1}$ and $J_{2}$ which are obtained via the subsystem model indicate that the obtained dynamic parameters are the better. Thus, the individuals have been updated before the evolution process ends, and the optimal result of the individuals is obtained.

(3) The process of genetic operations: Herein, the genetic operations have two process including crossover and mutation operations. This study chooses the crossover probability of 0.95 and mutation probability of 0.05 in $n=1000$ generations for the process of genetic operations. In the mutation operation of each individual with a probability of 0.05 , the new individual is then generated and added in the population. Finally, based on two fitness values of $J_{1}$ and $J_{2}$, only the better individuals have been selected to perform next generations. For the termination criterion, it is happen when the change of the $J_{1}$ or $J_{2}$ between two adjacent generations below $10^{-3}$, and the results of the congregation are then obtained. The MGA code is given in Table 1. 
Table 1. The code of the MGA program

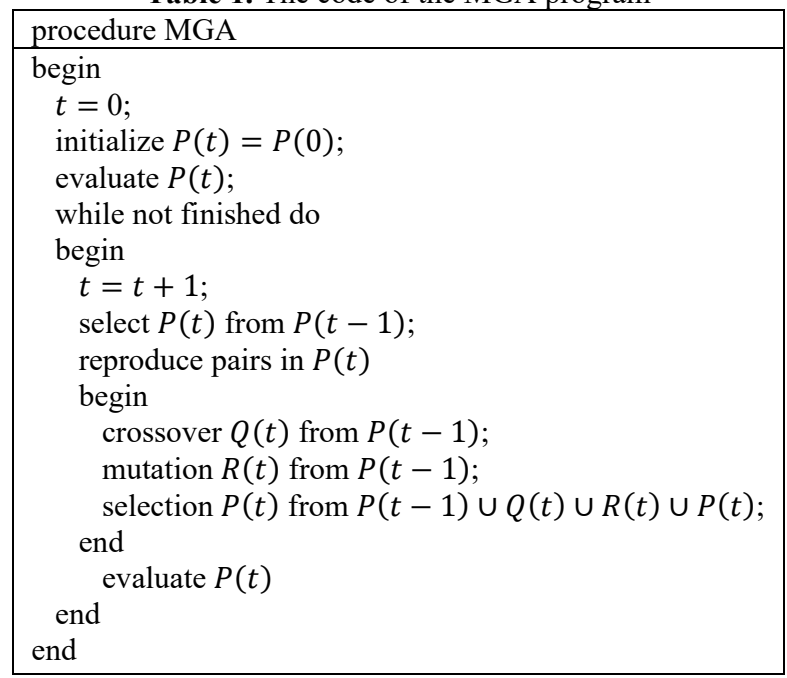

Table 2. Lumped parameters of heavy truck

\begin{tabular}{|c|c|c|c|c|c|}
\hline Parameter & Value & Parameter & Value & Parameter & Value \\
\hline$m_{a 1} / \mathrm{kg}$ & $0.45 \times 10^{3}$ & $K_{2} / \mathrm{N} \cdot \mathrm{m}^{-1}$ & $5.454 \times 10^{5}$ & $C_{c 1} / \mathrm{N} \cdot \mathrm{m} \cdot \mathrm{s}^{-1}$ & $0.75 \times 10^{3}$ \\
\hline$m_{a 2} / \mathrm{kg}$ & $1.025 \times 10^{3}$ & $K_{3} / \mathrm{N} \cdot \mathrm{m}^{-1}$ & $5.454 \times 10^{5}$ & $C_{c 2} / \mathrm{N} \cdot \mathrm{m} \cdot \mathrm{s}^{-1}$ & $0.75 \times 10^{3}$ \\
\hline$m_{a 3} / \mathrm{kg}$ & $1.025 \times 10^{3}$ & $K_{c 1} / \mathrm{N} \cdot \mathrm{m}^{-1}$ & $1 \times 10^{5}$ & $C_{S} / \mathrm{N} \cdot \mathrm{m} \cdot \mathrm{s}^{-1}$ & $0.2 \times 10^{3}$ \\
\hline$m_{t} / \mathrm{kg}$ & $12.5 \times 10^{3}$ & $K_{c 2} / \mathrm{N}^{\prime} \cdot \mathrm{m}^{-1}$ & $1 \times 10^{5}$ & $l_{1} / \mathrm{m}$ & 0.2 \\
\hline$m_{b} / \mathrm{kg}$ & $3.6 \times 10^{3}$ & $K_{S} / \mathrm{N} \cdot \mathrm{m}^{-1}$ & $2 \times 10^{4}$ & $l_{2} / \mathrm{m}$ & 0.8 \\
\hline$m_{c} / \mathrm{kg}$ & $0.5 \times 10^{3}$ & $C_{t 1} / \mathrm{N} \cdot \mathrm{m} \cdot \mathrm{s}^{-1}$ & $1.5 \times 10^{3}$ & $l_{3} / \mathrm{m}$ & 1.3 \\
\hline$m_{s} / \mathrm{kg}$ & $0.12 \times 10^{3}$ & $C_{t 2} / \mathrm{N} \cdot \mathrm{m} \cdot \mathrm{s}^{-1}$ & $3 \times 10^{3}$ & $l_{4} / \mathrm{m}$ & 0.3 \\
\hline$K_{t 1} / \mathrm{N} \mathrm{m}^{-1}$ & $6.9 \times 10^{5}$ & $C_{t 3} / \mathrm{N} \cdot \mathrm{m} \cdot \mathrm{s}^{-1}$ & $3 \times 10^{3}$ & $l_{5} / \mathrm{m}$ & 4.1 \\
\hline$K_{t 2} / \mathrm{N} \cdot \mathrm{m}^{-1}$ & $1.38 \times 10^{6}$ & $C_{1} / \mathrm{N} \cdot \mathrm{m} \cdot \mathrm{s}^{-1}$ & $7.029 \times 10^{3}$ & $l_{6} / \mathrm{m}$ & 6.9 \\
\hline$K_{t 3} / \mathrm{N} \cdot \mathrm{m}^{-1}$ & $1.38 \times 10^{6}$ & $C_{2} / \mathrm{N} \cdot \mathrm{m} \cdot \mathrm{s}^{-1}$ & $2.409 \times 10^{4}$ & $l_{7} / \mathrm{m}$ & 4.0 \\
\hline$K_{1} / \mathrm{N}^{\prime} \mathrm{m}^{-1}$ & $1.0210^{5}$ & $C_{3} / \mathrm{N} \cdot \mathrm{m} \cdot \mathrm{s}^{-1}$ & $2.409 \times 10^{4}$ & $l_{8,9} / \mathrm{m}$ & $1.2 ; 4.8$ \\
\hline
\end{tabular}

\section{Optimal results and discussions}

\subsection{Optimal results}

To find the optimal parameters for the heavy trucks, assuming that the vehicle travels under a random road surface of ISO level B at $72 \mathrm{~km} / \mathrm{h}$ forward speed. The vehicle's parameters as listed in Table 2 and its road surface excitation as plotted in Fig. 2 are chosen as the parameter inputs of the optimal model in Fig. 3. Additionally, based on the research results in Part-1, an optimal range of the vehicle dynamic parameters proposed to improve the vehicle ride comfort in Table 3 are used to limit the boundary conditions of the MGA. Therefore, the boundary conditions of the dynamic parameters for the MGA model are listed in Table 4. The MGA is then performed to find the optimal values of $J_{1}$ and $J_{2}$ in $n=1000$ generations.

Table 3. The optimal region of the vehicle dynamic parameters

\begin{tabular}{|c|c|}
\hline Stiffness parameters & Damping parameters \\
\hline$K=\{0.6$ to 1.0$\} \times K_{0}$ & $C=\{1.2$ to 1.6$\} \times C_{0}$ \\
\hline$K_{t}=\{0.8$ to 1.2$\} \times K_{t 0}$ & $C_{c}=\{1.2$ to 1.6$\} \times C_{c 0}$ \\
\hline$K_{c}=\{0.6$ to 1.0$\} \times K_{c 0}$ & $C_{S}=\{1.4$ to 1.8$\} \times C_{s 0}$ \\
\hline$K_{S}=\{1.6$ to 2.0$\} \times K_{s 0}$ & \\
\hline
\end{tabular}


VIBRATION RESEARCH OF HEAVY TRUCKS. PART 2: OPTIMIZATION OF VEHICLE DYNAMIC PARAMETERS. YONG YE, VANLIEM NGUYEN, YONGZHU HU

Table 4. The boundary conditions of the vehicle dynamic parameters for the MGA

\begin{tabular}{|c|c|}
\hline Stiffness parameters & Damping parameters \\
\hline $3.272 \times 10^{5} \leq K_{2,3} \leq 5.454 \times 10^{5}$ & $2.89 \times 10^{4} \leq C_{3} \leq 3.85 \times 10^{4}$ \\
\hline $0.612 \times 10^{5} \leq K_{1} \leq 1.02 \times 10^{5}$ & $2.89 \times 10^{4} \leq C_{2} \leq 3.85 \times 10^{4}$ \\
\hline $1.101 \times 10^{6} \leq K_{t 2,3} \leq 1.656 \times 10^{6}$ & $8.43 \times 10^{3} \leq C_{1} \leq 11.25 \times 10^{3}$ \\
\hline $5.52 \times 10^{5} \leq K_{t 1} \leq 8.28 \times 10^{5}$ & $0.9 \times 10^{3} \leq C_{c 2} \leq 1.2 \times 10^{3}$ \\
\hline $0.6 \times 10^{5} \leq K_{c 1,2} \leq 1.0 \times 10^{5}$ & $0.9 \times 10^{3} \leq C_{c 1} \leq 1.2 \times 10^{3}$ \\
\hline $3.2 \times 10^{4} \leq K_{s} \leq 4.0 \times 10^{4}$ & $0.28 \times 10^{3} \leq C_{s} \leq 0.36 \times 10^{3}$ \\
\hline
\end{tabular}

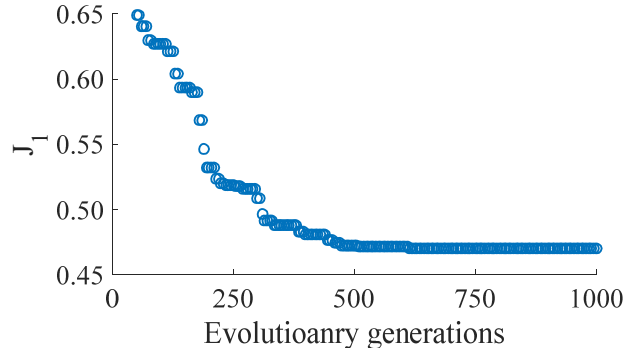

a) The fitness of the driver's seat vibration

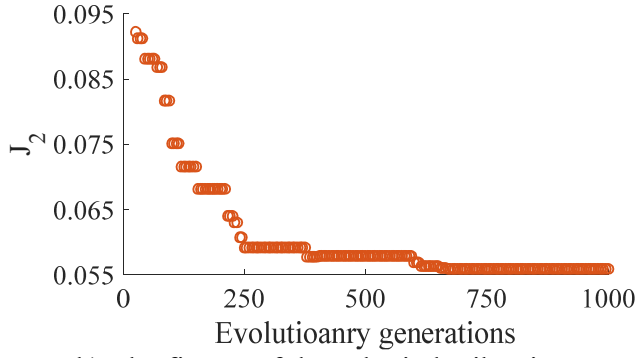

b) The fitness of the cab pitch vibration

Fig. 4. The curve of fitness values of the AGA

Table 5. The optimal results of stiffness parameters

\begin{tabular}{|c|c|c|c|c|c|c|c|c|c|}
\hline$n$ & $K_{S} \times 10^{4}$ & $K_{c 1} \times 10^{5}$ & $K_{c 2} \times 10^{5}$ & $K_{1} \times 10^{5}$ & $K_{2} \times 10^{5}$ & $K_{3} \times 10^{5}$ & $K_{t 1} \times 10^{5}$ & $K_{t 2} \times 10^{6}$ & $K_{t 3} \times 10^{6}$ \\
\hline 0 & 2.000 & 1.000 & 1.000 & 1.020 & 5.454 & 5.454 & 6.900 & 1.380 & 1.380 \\
\hline 1 & 3.112 & 0.911 & 0.922 & 0.889 & 0.443 & 0.463 & 7.876 & 1.554 & 1.665 \\
\hline 2 & 3.920 & 0.674 & 0.703 & 0.733 & 0.397 & 0.445 & 7.232 & 1.453 & 1.650 \\
\hline 3 & 3.612 & 0.766 & 0.754 & 0.765 & 0.532 & 0.543 & 6.804 & 1.389 & 1.445 \\
\hline 4 & 3.801 & 0.798 & 0.801 & 0.803 & 0.458 & 0.467 & 6.543 & 1.136 & 1.233 \\
\hline$\ldots$ & $\ldots$ & $\ldots$ & $\ldots$ & $\ldots$ & $\ldots$ & $\ldots$ & $\ldots$ & $\ldots$ & $\ldots$ \\
\hline 660 & 3.852 & 0.803 & 0.802 & 0.797 & 0.446 & 0.455 & 6.454 & 1.125 & 1.202 \\
\hline 662 & 3.841 & 0.810 & 0.813 & 0.754 & 0.424 & 0.434 & 6.354 & 1.122 & 1.119 \\
\hline 700 & 3.832 & 0.811 & 0.814 & 0.748 & 0.415 & 0.420 & 6.315 & 1.120 & 1.118 \\
\hline 701 & 3.832 & 0.811 & 0.814 & 0.744 & 0.415 & 0.418 & 6.313 & 1.120 & 1.118 \\
\hline 702 & 3.832 & 0.811 & 0.814 & 0.744 & 0.415 & 0.418 & 6.313 & 1.120 & 1.118 \\
\hline$\ldots$ & $\ldots$ & $\ldots$ & $\ldots$ & $\ldots$ & $\ldots$ & $\ldots$ & $\ldots$ & $\ldots$ & $\ldots$ \\
\hline 1000 & 3.832 & 0.811 & 0.814 & 0.744 & 0.415 & 0.418 & 6.313 & 1.120 & 1.118 \\
\hline
\end{tabular}

Table 6. The optimal results of the damping parameters

\begin{tabular}{|c|c|c|c|c|c|c|}
\hline$n$ & $C_{S} \times 10^{3}$ & $C_{c 1} \times 10^{3}$ & $C_{c 2} \times 10^{3}$ & $C_{1} \times 10^{3}$ & $C_{2} \times 10^{4}$ & $C_{3} \times 10^{4}$ \\
\hline 0 & 0.200 & 0.750 & 0.750 & 7.029 & 2.409 & 2.409 \\
\hline 1 & 0.322 & 0.927 & 0.855 & 10.011 & 2.842 & 2.935 \\
\hline 2 & 0.282 & 1.028 & 1.124 & 11.211 & 3.054 & 3.265 \\
\hline 3 & 0.351 & 1.151 & 1.054 & 9.895 & 3.112 & 3.273 \\
\hline 4 & 0.344 & 1.186 & 1.164 & 10.221 & 3.101 & 3.265 \\
\hline$\ldots$ & $\ldots$ & $\ldots$ & $\ldots$ & $\ldots$ & $\ldots$ & $\ldots$ \\
\hline 660 & 0.336 & 1.165 & 1.186 & 10.544 & 3.227 & 3.245 \\
\hline 662 & 0.332 & 1.162 & 1.183 & 10.522 & 3.352 & 3.364 \\
\hline 700 & 0.331 & 1.161 & 1.176 & 10.464 & 3.346 & 3.355 \\
\hline 701 & 0.331 & 1.161 & 1.173 & 10.465 & 3.342 & 3.351 \\
\hline 702 & 0.331 & 1.161 & 1.173 & 10.465 & 3.342 & 3.351 \\
\hline$\ldots$ & $\ldots$ & $\ldots$ & $\ldots$ & $\ldots$ & $\ldots$ & $\ldots$ \\
\hline 1000 & 0.331 & 1.161 & 1.173 & 10.465 & 3.342 & 3.351 \\
\hline
\end{tabular}

According to the optimization code of the basic genetic algorithm programs in Table 1 [19], 
an optimal program of the heavy truck dynamic model is developed and applied to find the minimum values of the $a_{w z}$ and $a_{w \varphi c}$. The results of the optimal running process are shown in Fig. 4. The results show that the Minimum fitness values of $J_{1}$ and $J_{2}$ are reached from the value 700 of evolutionary generation to the end. Thus, the optimization of the individuals is also obtained at the value 700 of generation. By decoding, the optimized values of the stiffness and damping parameters are presented in Tables 5 and 6 . The optimal values of the vehicle dynamic parameters are then used to compute and assess the optimal performance.

Based on the optimal results of vehicle parameters, the simulated results of the vehicle with the optimal parameters are simulated and compared with the original parameters under the same simulation conditions. The acceleration vibrations of the vertical driver's seat and cab's pitch angle; and their weighted RMS acceleration responses $\left(a_{w z}\right.$ and $\left.a_{w \varphi c}\right)$ are plotted in Fig. 5 and listed in Table 7. As shown in Figs. 5(a) and (b), the vertical driver's seat and cab's pitch angle accelerations with the optimal parameters of heavy trucks are significantly reduced in comparison without optimization. The obtained results in Table 7 showed that the weighted RMS accelerations of the $a_{w z}$ and $a_{w \varphi c}$ are significantly reduced by $26.3 \%$ and $35.3 \%$. According to the standard ISO 2631-1 (Table 1 of Part-1) [16], the driver felt a little not uncomfortable. Thus, the ride comfort of heavy trucks is remarkably improved by the optimization of the vehicle dynamic parameters on ISO lever B. To evaluate the optimal performance of the vehicle dynamic parameters under different simulation conditions, the different road surfaces and speeds are simulated and analyzed below.

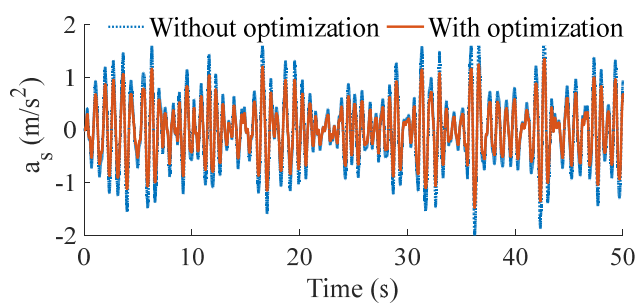

a) Driver's seat vertical acceleration

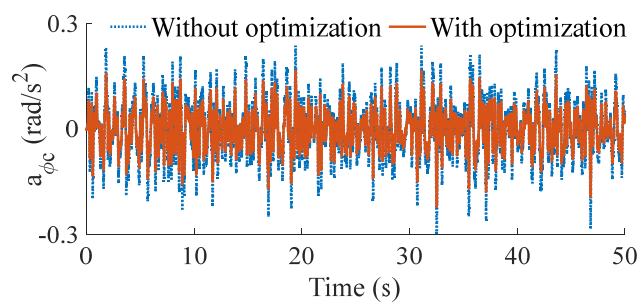

b) Cab pitch acceleration

Fig. 5. Optimal results of the acceleration vibrations of the cab and seat

Table 7. The comparison results of the optimal dynamic parameters

\begin{tabular}{|c|c|c|c|}
\hline Parameter & Without optimization & With optimization & Reduction \\
\hline$a_{w z}\left(\mathrm{~m} / \mathrm{s}^{2}\right)$ & 0.651 & 0.480 & $26.3 \%$ \\
\hline$a_{w \varphi c}\left(\mathrm{rad} / \mathrm{s}^{2}\right)$ & 0.085 & 0.055 & $35.3 \%$ \\
\hline
\end{tabular}

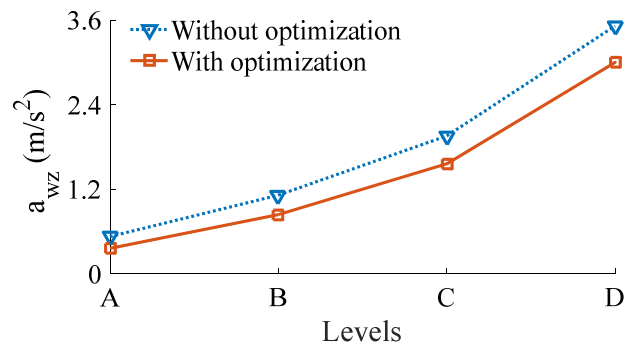

a) Driver's seat vertical acceleration

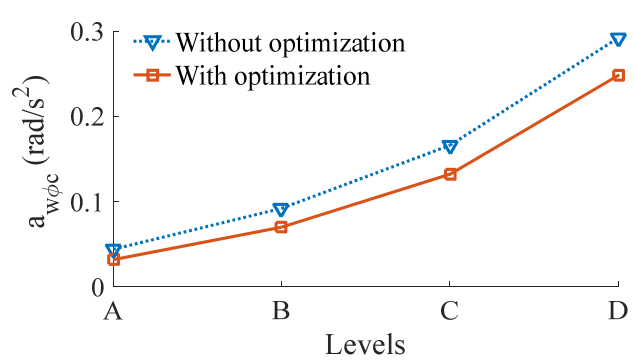

b) Cab pitch acceleration

Fig. 6. Result of the weighted RMS accelerations of the cab and seat under various road surfaces

\subsection{The optimal result under various road surfaces}

At the speed of the vehicle moving $72 \mathrm{~km} / \mathrm{h}$, four different road surface roughness of ISO level A (very good) to ISO level D (poor) have been used to evaluate the effect of road surface 
roughness on the effectiveness of the optimal parameters. The results of the $a_{w z}$ and $a_{w \varphi c}$ are shown in Fig. 6. It can see that all their values are significantly reduced compared to without optimization. Thus, with the optimal parameters, the vehicle ride comfort has been also enhanced under different simulation conditions of the road surfaces.

\subsection{The optimal result under various vehicle speeds}

The simulation of the vehicle with its optimal parameters over a range of vehicle velocities under the road surface roughness of the level B is plotted in Fig. 7.

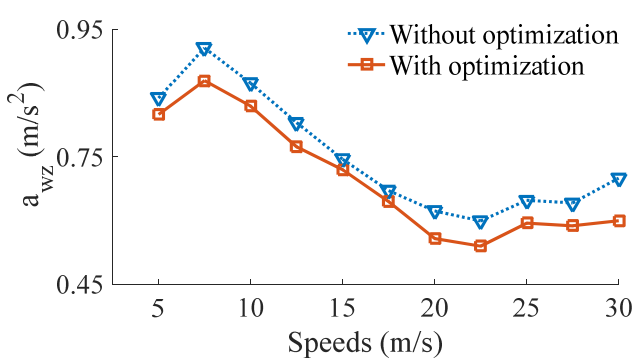

a) Driver's seat vertical acceleration

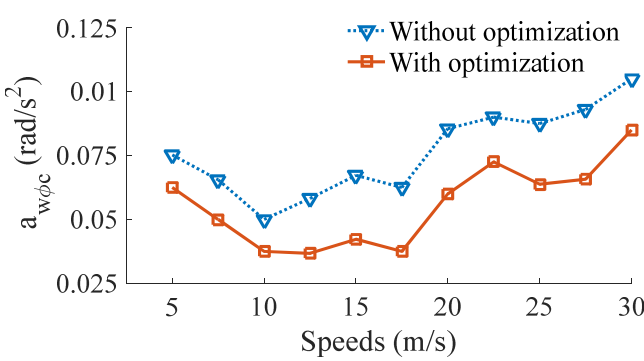

b) Cab pitch acceleration

Fig. 7. Result of the weighted RMS accelerations of the cab and seat under various vehicle speeds

Figs. 7(a) and (b) show that the $a_{w z}$ and $a_{w \varphi c}$ of heavy trucks are significantly reduced in comparison without optimization in all the different speed conditions of heavy trucks. The research result also shows that the speeds of heavy trucks strongly affect the vehicle ride comfort. Within the speed region from $5 \mathrm{~m} / \mathrm{s}$ to $15 \mathrm{~m} / \mathrm{s}(18 \mathrm{~km} / \mathrm{h}$ to $54 \mathrm{~km} / \mathrm{h})$ of the vehicle traveling, the weighted RMS acceleration of the vertical driver's seat is strongly increased, while the weighted RMS acceleration of the cab's pitch angle is minimum. It means that the cab shacking is improved, but the driver ride comfort is increased, thus, the drive feels uncomfortable when the vehicle moving at low speeds.

It is also found that the $a_{w z}$ and $a_{w \varphi c}$ are significantly reduced at the speed from $17.5 \mathrm{~m} / \mathrm{s}$ to $22.5 \mathrm{~m} / \mathrm{s}(63 \mathrm{~km} / \mathrm{h}$ to $81 \mathrm{~km} / \mathrm{h})$. It implied that the ride comfort of heavy trucks is clearly improved. On the contrary, with the increase of accelerations the speeds from $25 \mathrm{~m} / \mathrm{s}$ to $30 \mathrm{~m} / \mathrm{s}(99 \mathrm{~km} / \mathrm{h}$ to $108 \mathrm{~km} / \mathrm{h}$ ), all the $a_{w z}$ and $a_{w \varphi c}$ are increased, thus, the vehicle ride comfort is reduced. Based on the analysis results, a range of the vehicle speed from $17.5 \mathrm{~m} / \mathrm{s}$ to $20 \mathrm{~m} / \mathrm{s}(63 \mathrm{~km} / \mathrm{h}$ to $72 \mathrm{~km} / \mathrm{h})$ should be used to more enhance the ride comfort of heavy trucks.

\section{Conclusions}

Based on the analysis results of the influence of the dynamic parameters of heavy trucks on the ride comfort and the optimal region of the proposed parameters in Part-1, a multi-objective genetic algorithm is developed and applied to optimize the vehicle dynamic parameters. The research results show that the vehicle system with its optimal parameters can enhance the ride comfort under different simulation conditions. Especially, the weighted RMS accelerations of the $a_{w z}$ and $a_{w \varphi c}$ are significantly reduced by $26.3 \%$ and $35.3 \%$ under the ISO level B of the road surface.

The research results also noted that a speed region of the vehicle from $17.5 \mathrm{~m} / \mathrm{s}$ to $20 \mathrm{~m} / \mathrm{s}$ $(63 \mathrm{~km} / \mathrm{h}$ to $72 \mathrm{~km} / \mathrm{h})$ should be used to further enhance the ride comfort of heavy trucks.

This study not only provides a multi-objective optimal method for the parameters of heavy trucks to enhance the ride comfort of heavy trucks but also as the basis for the optimal design of the vehicle structure to improve vehicle stability and safety. 


\section{Acknowledgements}

This research was supported by Open Fund Project of Hubei Key Laboratory of Intelligent Transportation Technology and Device, Hubei Polytechnic University, China (No. 2020XY105) and Talent Introduction Fund Project of Hubei Polytechnic University (No. 19XJK17R).

\section{References}

[1] Li B. 3-D Dynamic Modeling and Simulation of a Multi-Degree of Freedom 3-Axle Rigid Truck. University of Wollongong, New South Wales, Australia, 2006.

[2] Jiao R., Nguyen V. Studies on the low frequency vibration of the suspension system for heavy trucks under different operation conditions. Journal of Noise and Vibration Worldwide, 2020, https://doi.org/10.1177/0957456520948271

[3] Lu S. Optimum design of "road-friendly" vehicle suspension systems subjected to rough pavement surfaces. Applied Mathematical Modelling, Vol. 26, Issue 5, 2002, p. 635-652.

[4] Yong Y., Ren W., Chen L., Jiang M., Yang Y. Study on ride comfort of tractor with tandem suspension based on multi-body system dynamics. Applied Mathematical Modelling, Vol. 33, Issue 1, 2009, p. 11-33.

[5] Nguyen V., Jiao R., Zhang J. Control performance of damping and air spring of heavy truck air suspension system with optimal fuzzy control. International Journal of Vehicle Dynamics, Stability, and NVH, Vol. 4, 2020, p. 179-194.

[6] Nguyen V., Zhang J., et al. Performance analysis of air suspension system of heavy truck with semi-active fuzzy control. Journal of Southeast University, Vol. 33, 2017, p. 159-165.

[7] Guglielmino E., Sireteanu T., Stammers C. W., Ghita G., Giudea M. Semi-active suspension control improved vehicle ride and road friendliness, New York: Springer Publishing Company, 2008.

[8] Sy D., et al. A hybrid clustering based fuzzy structure for vibration control - Part 2: An application to semi-active vehicle seat-suspension system. Mechanical Systems and Signal Processing, Vol. 450, 2015, p. 288-301.

[9] Michele I., Patrizio T., Mauro M. Development of a heavy truck semi-active suspension control. Control Engineering Practice, Vol. 14, 2006, p. 305-312.

[10] Sun Z., Zhang Z., He Y., et al. Research on improving the ride comfort of cab for heavy-duty truck. China Mechanical Engineering, Vol. 15, Issue 17, 2004, p. 1584-1586.

[11] Nguyen V., Zhang J., et al. Study of fuzzy control for cab's isolation system of heavy truck. Vibroengineering Procedia, Vol. 10, 2016, p. 309-314.

[12] Chen Y., Zhong L., et al. Hybrid fuzzy skyhook surface control using multi-objective microgenetic algorithm for semi-active vehicle suspension system ride comfort stability analysis. Journal of Dynamic Systems, Measurement, and Control, Vol. 134, 2012, p. 041003.

[13] Zhang Z., Lu P. Optimization method of suspension parameters for articulated vehicle based on ride comfort and road -friendliness. Journal of Traffic and Transportation Engineering, Vol. 9, Issue 5, 2009, p. 49-354.

[14] Zhang J., He Y., Yang H. Modification of cab suspension system based on pitch angular acceleration. China Mechanical Engineering, Vol. 23, Issue 18, 2012, p. 2258-2262.

[15] Mechanical Vibration-Road Surface Profiles - Reporting of Measured Data. ISO 8068, 1995.

[16] Mechanical Vibration and Shock-Evaluation of Human Exposure to Whole Body Vibration -Part 1: General Requirements. ISO 2631-1, 1997.

[17] Nguyen V., Jian R., et al. Performance analysis of semi-active hydraulic system of the off-road vibratory roller cab using optimal fuzzy-PID control. Journal of Central South University, Vol. 35, 2019, p. 399-407.

[18] Nguyen V., Zhang J., Yang X. Low-frequency performance analysis of semi-active cab's hydraulic mounts of an off-road vibratory roller. Shock and Vibration, Vol. 2019, 2019, p. 8725382.

[19] Zadeh N., Salehpour M., Jamali A., Hanghgoo E. Pareto optimization of a five-degree of freedom vehicle vibration model using a MUGA, Engineering Applications of Artificial Intelligence, Vol. 23, Issue 4, 2010, p. 543-551. 


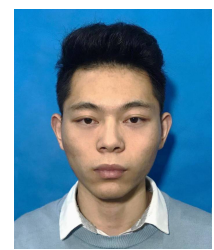

Yong Ye is the student at School of Mechanical and Electrical Engineering, Hubei Polytechnic University, Huangshi City, China. His current research interests include vehicle dynamics, vibration and optimization control.

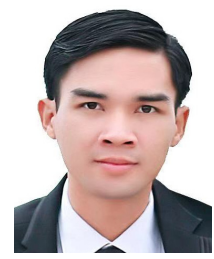

Vanliem Nguyen (Corresponding author) received Ph.D. degree in School of Mechanical Engineering, Southeast University, Nanjing, China, in 2018. His current research interests include vehicle dynamics, vibration and optimization control, lubrication and tribology. ORCID iD: https://orcid.org/0000-0001-8772-1086

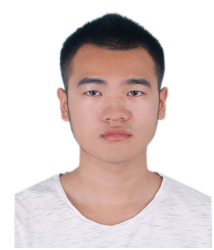

Yongzhu Hu is the student at School of Mechanical and Electrical Engineering, Hubei Polytechnic University, Huangshi City, China. His current research interests include vehicle dynamics, vibration and optimization control. 